\title{
The Role of Information Technologies in the Innovative Potential of the Artistic Museum
}

\author{
Tatiana V. Portnova \\ Doctor of Art History \\ Professor of the Institute of Slavic culture \\ of the Department "The Art of Choreographer" \\ of the Institute of Arts of the Department "Art History" \\ A.N. Kosygin Russian State University, Moscow
}

\begin{abstract}
The article discusses the issues of the penetration of information technologies into the museum environment and their use in the educational process of future art historians. Close cooperation between geographically remote artistic monuments and their study by means of interactive systems is one of new paradigms that became possible due to the progress of new technologies. The education of artists and art historians in the field of new technologies lies in the fact how they can be used in the creation of new art forms as well as the exposure methods of art works. This is another area on which modern museum experts and art historians are working.
\end{abstract}

Keywords-Information technologies; Art works; Museum environment; Learning methodology; Training of an art historian

\section{INTRODUCTION}

In the system of modern science, the study of art works with the help of media has a special place. From a special field of an art cycle, it is now transformed into a broad field of interdisciplinary nature. Future artists and art historians still have not reached that level of technical competence, which is necessary for the realization of their own artistic potential through new technical capabilities. These capabilities make it possible to form an idea about the body of art works that emerged in the course of historical, social and cultural development in a particular era; to form the skills of research methods of using various types of information sources in institutional and post-graduate academic practice, to determine the specificity of art historical and cultural studies and tasks of historiographic images; to lay the foundations of the organization of independent sources search, historiographic representational iconography, and methods for studying the works of graphic art, painting, sculpture, and decorativeapplied art. The importance of information fundamentals of sources search, as well as studying the methods of the treatment of sources, determines the strength of acquired knowledge and its use in future institutional practice and independent activities. In the independent study and creative work of students on the periphery, the Internet often becomes the only source of information about fine and applied arts, architecture, and design, as, despite a relatively high cost, it is still cheaper than the high-quality reproductions albums, not to mention the speed of access and the absence of restrictions. Currently, the network provides quite ample opportunities for a variety of textual and visual information on the classical and contemporary art. The user who knows the English language, even at an average level, can access the resources of UNESCO, the largest museums and private galleries.

A contemporary museum of the $21 \mathrm{st}$ century is characterized by the shift in the understanding of its mission. In the 19th-20th centuries, a museum was seen primarily as the church, which collected and stored objects of cultural heritage, but a contemporary museum, retaining its traditional functions, is seeking maximum completeness to demonstrate the diversity of cultural values stored not only in exposure but also in the funds. The ideas of spirituality and the preservation of cultural memory are directly connected with the traditional mission of a museum developed in the works (Kovalyov, 2009; Mastenitsa, 2015; Rosenberg, 2013; Thompson, 2009). The strategy of information-project development of museum collections, which could contribute to strengthening, but not weakening cultural identity, studying and promoting of the works of art and museum environment's objects, is shown in other studies (Devine, 2013; Flannery, 2008; Lehn, \& Heath, 2005; McWilliams, 2014; Pertsev, 1991). Information technologies allow introducing to the visitor those objects that are stored in funds and were not previously available. Information technologies in the context of the exhibition activities and in practice can provide invaluable assistance in improving the methods of presentation of museum collections. However, new media technologies contribute to public education via the websites of museums (Rosa, 2015; Vitali, 2016).

The goal of the article lies in revealing the role of information technologies in the study of art monuments, revealing the specificity of development of the multimedia direction of art museums, formulating a complex of interrelated theoretical and methodological principles for development of information culture of future art historians in the context of global computerization.

The relevance of the information source of the preparation of a future art historian is obvious, because in today's world, there is virtually no technology of historical cognition without the use of source analysis. Original visual sources, which art deal with, are paramount; they did not need to prove their practical significance. Contemporary art history faces the tasks related to the need for further development and expansion of 
information technologies in historical study of art. Their introduction not only into scientific use, but also in student practice of future art historians takes on great importance.

\section{MethodS}

The role of information technologies in the study of art is explored in the unity of artistic and aesthetic, methodological and technological problems. The methodological guide of the research is classification and typological approaches that reveal the shape and range of the use of computer technologies in the museum environment. Analyzing the current trends in art and museum practice, establishing their relationship with the development of digital technologies, the author uses a systematic approach and structural analysis method, which make it possible, on the basis of a synthesis of different knowledge, to describe the phenomenon of multimedia technologies as a new phenomenon in the design of art culture. The ability of virtual space to intensify the viewer's emotional response, personal experience of the exhibition situation determines the humanist potential of the multimedia culture of a museum and opens up new possibilities of artistic design.

\section{RESULTS}

The study of art history, where a certain number of hours are devoted to independent study, the ability to work with information materials, including electronic resources, assumes special significance. It is important to note that when dealing with a work of art on the Web site, there appears the illusion of "intimacy", impossible in a museum or at an exhibition when the viewer is among other people. However, this seeming comfort of perception may lead to the emergence of another vision, the birth of imitative art culture that will be destroyed only with a meeting with the originals.

The application of new courses related to information technologies in a museum, dealing with information carriers in a museum, electronic MUSEUM and interaction "visitorcomputer", "digital" art space, etc. is important for a modern art historian (Marty, 2005; Friedman, 1983; Trafí-Prats, 2009). Initially, it is necessary to uncover the role of information technologies in today's global society and humanitarian culture; to highlight the most important areas of information technologies in a modern museum: databases, multimedia technologies, to get acquainted with the history of the informatization of museums, modern domestic and foreign achievements through the example of the most prominent museums in the world; to give presentations on important national information systems used in the world's museums and the practical skills of working with them (Luke, 2002; Lydens et al., 2007; Virtual Museum of Canada, 2011; Art Project, 2011; Complex Automated Museum Information System, 2011).

It is reasonable to divide the structure of courses into two parts. The first one should be a summary of the scientific and general cultural bases of informatics, causes of its appearance, the general principles of the functioning of the human brain and computer. In the second part, it is necessary to study the history and main areas of the use of information and communication technologies in museums (museum data retrieval systems that are based on electronic databases, multimedia and the Internet). Computers are now firmly entrenched in museum activities, but the most relevant is not to the instrumental role of new technologies but the possibilities of their use to enhance the capacity of a traditional museum. Moreover, it is particularly interesting to assess whether technologies may fundamentally influence the conservative museum institute, open new horizons in the virtual space, try to imagine the future of the museum, which, without doubt, is closely connected with the general course of cultural evolution. "The mission of a museum in the 21 st century is presented as the task of active participation in the creation and development of the cultural landscape, geographically and socially defined by the scale and significance of the museum, cultural adaptation, preservation of cultural and historical ties with the previous epochs, cultural heritage in the new virtualized cultural landscape" (Ovchinnikova., 2017)

The basis of the information material is museum and art databases. Information technologies are widely used at present in all spheres of activities of a museum (accounting-fund, scientific, exhibition, restoration, and publishing). Modern information technologies when working with collections allow avoiding: multiple duplicating of the same information, distortion of information, complexity of the changes entering, ineffective search, and insufficient accessibility for users. The informatization of resource functions of a museum is going on, i.e. the creation and representation in the open information space of electronic publications about a museum, its activities and its collections, and the organization of free access to information in this space (Gelman, 2009; Drikker, 1999, 2001; Lebedev, 2005; Nenakhova, 2014; Nol, 2007).

Electronic expositions can help in the study of certain periods of development of domestic and foreign art. Certainly, electronic exposition is not just an interface, which gives a visitor access to electronic catalogue. It is based on its own scenario. This can include specially designed texts of multimedia programs, video materials, etc. They have a synchronization mechanism. Therefore, electronic exposure is differently correlated with real museum exhibitions and represents the rational development, focused on attracting visitors. Exposition space gradually transforms into a virtual environment, and they begin to interact in a complicated manner, involving into this interaction a "museum visitor". The exposition of art exhibition or museum exhibition is introduced into the plot, becomes the defining constructive factor that has an impact on the nature of the audience's perception. Typically, electronic expositions convey the process of their demonstration, which determines the form of the present time and the continued fixation of impressions, through which the promotion of the story of the exhibition is carried out. At the same time, at such expositions the main attention is directed to the "variability" of the audience's perception, it is that stands here as an independent style-forming factor.

The palette of artistic opportunities of information technologies today is significantly expanding through computer 3D modeling. It was invented as a tool of architect, and that's why the use of $3 \mathrm{D}$ graphics programs is most effective where the object of interpretation is the architectural structure or part thereof - in museums-reserves and in museums, located in the 
monuments of architecture. Computer graphics comes to the aid of restorers that allows seeing the structure of threedimensional structures. Illusory volume and depth give an idea of the external and internal structure of the object, help see their mutual dependence.

Another source of studying art is electronic publications on CD-ROM, which appeared in 1994. They are designed as "multimedia applications" of various subjects, city guides, museums guides, encyclopedias and guides of art and culture. Most of these discs represent the electronic kind of albums with pictures and text. Electronic publications in CD-ROM are built like books that make not only watch reproductions, but also think, match the facts, take out from them the essence of the studied material. Sometimes, the texts contained in them are commented referring to the appropriate source that gives them a scientific description. As additional material, DVD video programs on certain topics can be used, the benefit of which over other visual materials is the ability to combine into a computer system text, audio, animation, and video images. Electronic guides of "new wave", created in recent years, have a more complicated structure and are incomparably richer in content; they use modern design and improved navigation methods. The ways of presenting information in these guides are very diverse (text, images and objects of rotation, panoramas, animations, interactive graphics, video fragments, lectures, and musical accompaniment. This active internal circulation of external information at different levels of perception of the movie, on which it is subjected to the influence of the subjective world of the production director, i.e., the author of the video, is kind of illuminated, displayed by his feelings, thoughts, will, memory, feelings, associations, etc. and is in essence a functional basis of the perception of artistic image as a specific spiritual activity. The disks are created, focused on professional users (art historians, restorers, monuments preservation workers, students of the respective specialties). The information included in the DVDs obtains multidimensionality and semantic complexity thanks to the presence in each of them of a distinctive identity of the author (production director and commentator). Ultimately, everything is determined by the depth of the question, the art credibility of on-screen incarnation. A professionally filmed exposition leads the visitor after it, and he/she, in turn, following the multimedia technologies, is increasingly immersed into it. So, the authors of the films on the discs by Audio Logos, in particular, the "Greatness of the Legendary Hellas" (from myths to stories), stop their choice on the most significant monuments of Greece, located in the following regions: Athens, Delphi, Mycenae. The exposition of the halls of the Museum of Delphi, well thought out and spectacularly demonstrated, gives the viewer the opportunity to enter into their space that constantly transforms and flows. The effect of permanent displacements not only in space but also in time is enhanced thanks to the historical renovations created by multimedia and lighting means.

Another series of discs "The History of the Fine Arts and Architecture of the Italian Renaissance", produced by Italian cinema Luce institute, is built on the scientific and chronological statement of creativity of craftsmen from the Proto-Renaissance, represented by Giotto till late Renaissance, shown by Titian's oeuvre. This artistic epoch, stretched for five centuries, demonstrates the formation of something completely new compared with the middle ages, a system of vision and artistic display of the world. The panoramic shooting of frescoes from a height of 50 meters in a movie about Giotto, never fading scenic coloring of the works by Correggio, gathered together from various museums in the world, the universal creative personality of Leonardo da Vinci, his discoveries in science, shown in graphic sketches, drawings, anatomical engineering sketches, as well as included memories of his contemporaries, are combined with logic and documented commentaries of the text's author.

There are discs focused on the author's narration of the topic by an art historian with a parallel display of art monuments - originals located in geographical places of their locations and storage. So, the collector's edition "History and Art" of the production of BBC, United Kingdom with the stories about ideas and values of Western civilizations of the middle ages and modern times of the famous historian and art historian Lord K. Clark is valuable by the fact that the viewer appears beside him and travels with him through various cities of Europe.

To the same company BBC belong the other aspects of the study of art works, namely the analytical description of some specific masterpiece. The cycles of films "The Power of Art" and "Private Gallery" with the disks: Bernini's "The Ecstasy of St. Theresa", Rembrandt's "The Return of the Prodigal Son", P. Picasso's "Guernica", etc., deliberately avoid staged scenes and talk about the creations by the language of the artists themselves.

Thus, the history of artistic creations, collections and at the same time museum multimedia, captured on a two-dimensional film plane, here appeared to be passed and lived. We observe connection of all the paths: a museum item, museum multimedia and the author himself. The new status of a number of Museums is defined by creating their own libraries, including movies and educational programs based on their own collections that facilitate the growth of young art historians. The educational fund of virtual museums may include books, albums, videos, CDs, slides, and computer programs. A multimedia library may combine programs on various topics on the theory and history of art, museum collecting, study and display of exhibit items. The great potential of the library can be used in teaching students - art historians in accordance with the plans and standards of higher vocational education, it can be adapted to a specialized copyright courses and included in education environment. That is why we have the task of creating methodical recommendations for systematization of the multimedia database of museums and the formation of the individual sections of topics depending on the specificity and the representation of the material in the course of studied disciplines. In addition, in carrying out various training exercises and research projects, the funds of multimedia libraries can help students and aspirants of cultural departments in their professional activities (Lebedev, 1998; Maystrovich, 2008; Sinitsyna, 2009). They complement the direct communication with art works, form the professional vision of a future specialist, the ability to correlate with those obtained in the process of studying art knowledge: the ability to make 
expert opinions on the work, capacity for analytical research at the stylistic and figuratively-semantic levels,

Today, information technologies are widely used at various stages of the life cycle of exhibitions and expositions in a contemporary museum - since the establishment of scientific and artistic concept of the exposition and till its implementation in exhibition halls. The selection and analysis of materials, the preparation of documentation for exhibitions and expositions is the most important element of the exhibition activities. Already during the preliminary stage of the preparations for the exposition, selecting and analyzing collection material, an employee of Museum may refer to the data retrieval system and get a list of those items that match the selected criteria (for example, by dates, genre, plot, etc.). However, if there is bank of digitized images, an art historian has the ability to select material by analyzing the figurative variety presented on the monitor screen, which greatly simplifies the subsequent phase of work directly with works in storerooms. A multimedia exposition is a qualitatively new stage of mutual connection of a museum and multimedia. It is created in the tipping point when multimedia technologies are no longer a tool and are woven directly into the fabric of a museum's activities.

\section{CONCLUSION}

So, this clearly demonstrates that the modern study of art today is accompanied by a dynamic development of Internet resources and effective use of information technologies in educational practice. They are a powerful tool that allows supplementing the lecture classroom material with diverse interpretations. The combination of diachronic and synchronic approaches, for example, plays an important role in studying the art of past eras. Now it is no longer just about creating content, but about the structuring and development of scenarios of multimedia programs and websites, diagrams of hyperlinks, description formats, and linguistic descriptions of information systems. At the modern stage art history in information systems acquires its subject, acquires scientific tools and analysis techniques. The case is not limited to disclosing the secrets of multimedia technologies. Museum multimedia should be the intersection of historical and contemporary technologies, fictional and real spaces and, finally, various types of museum activity.

It is necessary to explore more fully the principle of prospective cultural thematic planning of art historian cycles, precisely and deeply consider general problems and individual designs in their implementation of information systems. On the other hand, the main feature of art studying of art monuments is the dependency of this study on the condition and requests of live educational practice. Only in this way, one can gain organic unity, where the traditional classical learning and electronic resources are not mutually exclusive but enrich each other.

\section{REFERENCES}

[1] Gelman, M. (2009). Artist and Internet are the Messengers of the Future in the Country of Past. In EVA'09 (pp. $8 \sim 1 \sim 1-8 \sim 1 \sim 2$ ). Moscow.

[2] Drikker, A.S. (2001). Evolution of Culture: Information Selection, St. Petersburg: Akademicheskii proekt. (p. 182).

[3] Drikker, A.S. (1999). Art Museum and Global Networks. In Abstracts of the International Conference "Internet - Society - Personality" (pp. 1012). St. Petersburg: The Open Society Institute.

[4] Kovalyov, A. (2009). To the Question about the Impossibility of Digital Art. In EVA'09 (pp. $8 \sim 2 \sim 1-8 \sim 2 \sim 2$ ). Moscow.

[5] Lebedev, A.V. (2005). Information Technologies in Museum Affairs. In The Basics of Museology: Work Book. Moscow. (p. 205).

[6] Lebedev, A.V. (1998). Methodology and Practice of Electronic Publications on Art. Moscow: Research and Development Establishment of the Russian Academy of Arts. (p. 56).

[7] Maystrovich, T.V. (2008). Libraries and Museums in the Context of "Personal Cultural Institutes". In EVA'2008 (pp. $7 \sim 2 \sim 1-7 \sim 2 \sim 2$ ). Moscow.

[8] Mastenitsa, E.N. (2015). The Social Functions of Museum in a Global World. In The Proceedings of St. Petersburg State Institute of Culture and Arts. Vol. 210: St. Petersburg S.N. Ikonnikova's Historical Culturological School: History and Modernity (pp. 229-236). St. Petersburg.

[9] Nenakhova, N.N. (2014). Information - Promotional Components and Functions of Museum Activities. The World of Science, Culture, and Education, 1, 323-325.

[10] Nol, L.Ya. (2007). Information Technologies in Museum's Activities. Moscow. (p. 114).

[11] Ovchinnikova, Z.A. (2017). Museum in the Context of Socio-Cultural Transformations of Information Society. Bulletin of Culture and Arts, 3(51), 43-47.

[12] Pertsev, D.G. (1991). The Scientific Problems of Computerization of Art Museums. In Computer in Museum, Museum in Computer (pp. 22-26). Moscow: State Tretyakov gallery.

[13] Rosenberg, O.F. (2013). Socio-Cultural Functions of Modern Private Museums. The World of Science and Art: The Questions of Philology, Art History and Cultural Studies, 26, 25-30.

[14] Sinitsyna, O. (2009). The Problem of Search of High-Quality Electronic Resources on Art in the Internet. In EVA'09 (pp. 7 8 1). Moscow.

[15] Thompson, O.I. (2009). New Technologies and Cultural Heritage. Moscow. (p. 111).

[16] Art Project. (2011, March 30). Retrieved May 6, 2018, from http://www.googleartproject.com

[17] Virtual Museum of Canada (VMC). (2011, March 30). Retrieved May 6, 2018, from http://www.museevirtuel-virtualmuseum.ca

[18] Complex Automated Museum Information System. (2011, March 28). Retrieved May 6, 2018, from URL: http://www.kamis.ru

[19] Devine, J. (2013). Voices from the Past: Presenting (re)Constructed Environments through Multimedia Technologies. In Presenting the Romans: Interpreting the Frontiers of the Roman Empire World Heritage Site (pp. 113-118). Boydell \& Brewer, Boydell Press.

[20] Flannery, M. (2008). Visual Technologies. The American Biology Teacher, 70(4), 241-245.

[21] Friedman, A. (1983). The New Technologies and Museum Education. Roundtable Reports, 8(5), 12-14.

[22] Larkin, C. (2010). Looking to the Future While Learning from the Past: Information Seeking in the Visual Arts. Journal of the Art Libraries Society of North America, 29(1), 49-60.

[23] Lehn, D., \& Heath, C. (2005). Accounting for New Technology in Museum Exhibitions. International Journal of Arts Management, 7(3), 11-21.

[24] Luke, W. (2002). Strange Attractor: The Tech Museum of Innovation. In Museum Politics: Power Plays at the Exhibition (pp. 186-202). University of Minnesota Press. 
[25] Lydens, L., Saito, Y., \& Inoue, T. (2007). Digital Technology at the National Science Museum of Japan. The Journal of Museum Education, 32(1), 7-16.

[26] Marty, P. (2005). So You Want to Work in a Museum . . . Guiding the Careers of Future Museum Information Professionals. Journal of Education for Library and Information Science, 46(2), 115-133.

[27] McWilliams, F. (2014). A Sense of Place: Digitally Mapping Museum Collections. Journal of Museum Ethnography, 27, 46-62.

[28] Rosa, C. (2015). Preserving New Media: Educating Public Audiences through Museum Websites. Journal of the Art Libraries Society of North America, 34(1), 181-191.

[29] Trafí-Prats, L. (2009). Art Historical Appropriation in a Visual CultureBased Art Education. Studies in Art Education, 50(2), 152-166.

[30] Vitali, V. (2016). A Museum Is a Museum Is a Museum Is a Museum: Museums and Networks. In Remix: Changing Conversations in Museums of the Americas (pp. 100-104). University of California Press. 